\title{
VIRTUAL EDUCATION SPACE REALIZATION AS AN INTERNET OF THINGS ECOSYSTEM
}

\author{
Konstantina Gramatova $^{1}$, Stanimir Stoyanov ${ }^{1^{*}}$ \\ AND IVAN POPCHEV ${ }^{2}$ \\ ${ }^{1}$ Faculty of Mathematics and Informatics, University of Plovdiv "P. Hilendarski", \\ 236, Bulgaria Blvd, 4027 Plovdiv, Bulgaria, \\ e-mails: konstantina.gramatova@gmail.com; stani@uni-plovdiv.net \\ ${ }^{2}$ Faculty of Economy and Social Sciences, University of Plovdiv "P. Hilendarski", \\ 24, Tzar Asen St., 4000 Plovdiv, Bulgaria, \\ e-mail: ipopchev@iit.bas.bg
}

\begin{abstract}
This paper describes the conceptual and technological definition and integration of a Virtual Education Space (VES) into the Internet of Things (IoT) paradigm as an IoT ecosystem via a software integration platform (VES IoT Integration Platform, VIIP). The internal structure, architecture and characteristics of VES are described. The VES conceptual hierarchy entity model is presented as well as its conceptual equality with the IoT paradigm is analyzed. A conceptual integration based on the provided VES model is made within the IoT stack to ensure the full educational ecosystem compliance with the paradigm. The VIIP is presented and validated via analyzing the integration of electronic testing in the presented integration platform by following a common integration methodology defined for the VIIP.

Keywords: Internet of Things, Ecosystem, Education, VES Conceptual Model, IoT Integration Platform.
\end{abstract}

\section{INTRODUCTION}

The role of Internet as a massive access provider to all kinds of services and resources influences strongly the data, provisioning and processes virtualization extent in more and more aspects and domains of different nature. Since access is no longer an issues the emphasis is put on the way these services and resources can be combined and realized to achieve an intelligent self-adjustable behavior that is best suited for each user or service they interact with. The

\footnotetext{
${ }^{*}$ Corresponding author.

DOI: $10.7546 /$ EngSci.LV.18.01.01
}

(c) Инженерни науки, год. LV, 2018, № 1

5

(C) Engineering Sciences, LV, 2018, No. 1 
platforms providing these services and resources must be flexible enough to handle the dynamicity of the environment they are supposed to act in since a full virtualization of the physical world is meaningful if it manages to achieve a consistent virtualization of each and every aspect of it. The web-based educational platforms are affected by this evolution and must fit in to overcome the current issues they are facing as well as to comply with the evolving users' requirements and needs towards educational services and resources. In the light of this tendency the Faculty of Mathematics and Informatics at the University of Plovdiv develops a Distributed eLearning Centre (DeLC) project whose main goal is to provide a suitable infrastructure and digital environment for educational services and content provisioning by combining and utilizing different communication and software technologies $[1,2]$. These characteristics, however, turn out to be insufficient for a full virtualization of the educational process to be achieved by DeLC. Education itself is a multilateral process that depends on events and actions emerging at different time and at different locations - aspects of the real physical world and environment that the education exists in. The disconnection from the physical environment is a major problem for many educational web-based approach implementations as well as it is for DeLC. The different educational aspects (learning, assessment, self-education, etc.) are all interconnected and have an influence on each other and it must be made possible to create relations between them in order to fulfill a fully adaptive and user-centric personalized educational process, thus, achieving an effective educational virtualization. This leads DeLC to its natural next evolutionary stage where it is being transformed into a new infrastructure known as Virtual Education Space (VES) where users, time, location, autonomy and context-awareness are founder concepts that ensure a unified processing and interpretation of the information that is received both from the virtual environment and the real physical world [3]. VES is an intelligent space where its inhabitants can interact and communicate between each other in an intelligent anywhere - any time - anyhow manner. The Internet of Things (IoT) concept applies easily to such an environment. The Internet of Things is an extension of the Internet into the real physical world in which physical entities (objects, devices, things) are interconnected [4]. It defines an ecosystem composed of things that can sense the environment changes, analyze these changes based on a shared gained knowledge and act or make plans accordingly for achieving a personal or a shared goal. Bringing eLearning in the terms of IoT is the way to ensure it can keep up with the users' requirements and needs as well as with the Internet evolution.

(c) Инженерни науки, год. LV, 2018, № 1 6 1 (c) Engineering Sciences, LV, 2018, o. 1 


\section{VES OVERVIEW}

The vast and pervasive Internet application and its continuous transformation from a network of networks into a network of things [5], as well as the globalization of the cyber space, are the base for the rapid development of the cyber-physical social systems which will inevitably lead to major technological, economic and social consequences in the years to come.

\subsection{VES characteristics}

VES is an intelligent space [6, 7]. In comparison to DeLC, the intelligent educational space will effectively support the processes of blended education that integrates the electronic educational forms with the real educational processes. VES is context-aware. According to the definition of context [8] VES is defined as a context-aware system [9] via using and applying the Calculus of Contextaware Ambients (CCA) [10,11] for achieving the full context-awareness of the educational space via an integration of AJTempura [12, 13]. VES is scenariooriented. The educational scenarios are developed as workflows that consider the state changes of the environment, thus, they can adjust themselves based on the received information that could be about temporal characteristics of the educational processes (duration, repetitiveness, frequency, beginning, end) or events (planned or incidental). VES is with a controlled infrastructure. The access to the space is made possible via two types of predefined entry points with a different specialization level - Personal Assistants (PA) and the educational DeLC portal. Controlling the access to VES via personal assistants ensures the personalization and the intelligent behavior and provisioning of the required educational services and resources which is a key concept that is significant for the behavior of VES in a social and a personal aspect.

\subsection{VES architecture}

The approach adopted for the design and realization of the architecture of VES (Fig. 1) is based on two general concepts - seamless access to its functionalities via service provisioning and integrating a multi-agent platform to ensure the intelligent and proactive behavior of the services as well as their interaction and inner communication for achieving a fully personalized and intelligent educational process. The assistants are the key concept in VES. They are implemented as BDI $[14,15,16]$ agents and are active context-aware components that operate autonomously, reactively, proactively and socially and are responsible for supporting each participant and component in the space

(c) Инженерни науки, год. LV, 2018, № 1

(C) Engineering Sciences, LV, 2018, No. 1 


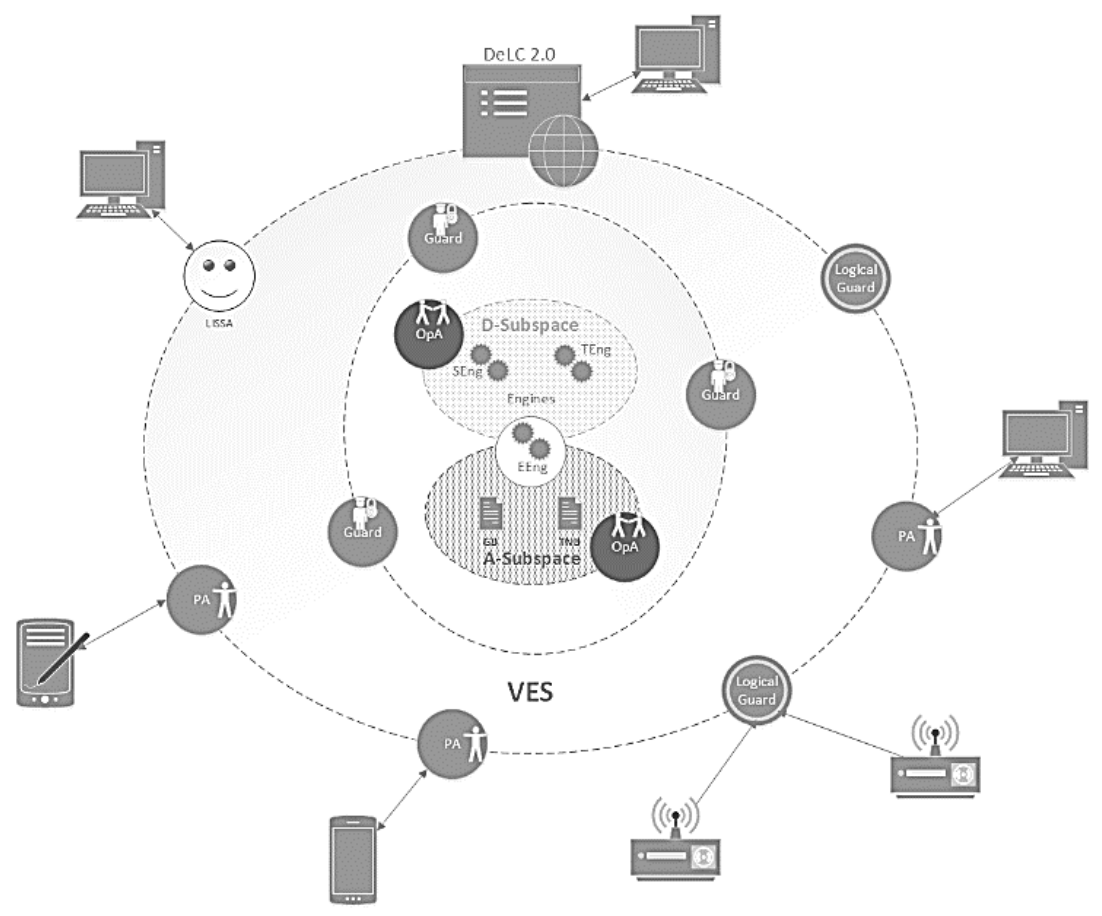

Fig. 1. VES architecture

Фиг. 1. ВОП архитектура

for achieving the optimal effectiveness and intelligence of the processes via cooperation among each other, between them and all the other VES components as well as with the physical world. There are three types of assistants defined - personal, operational and guards. The PA [14] are the personalized entry points of VES acting as an interface between the users of the physical world and the virtual environment of the space. There is a prototype of a PA for students in VES - Learning Intelligent System for Student Assistance (LISSA) [17] that integrates a simplified interface for comprehension and generation of natural language phrases. The PAs can be used by and on mobile devices (mobile PA, mPA). The main goal of the Operational Assistants (OA) is the support and management of educational scenarios execution and management. OA implement the intelligent communication between the server components and all other components in the space which defines them as a specific interface between that static services and data and the dynamic virtual environment of the space. Based on the functionalities OA provide, two subspaces could be distinguished in VES - DiLibs Subspace (D-Subspace) and Admin-Subspace

(C) Инженерни науки, год. LV, 2018, № 1

8

(c) Engineering Sciences, LV, 2018, No. 1 
(A-Subspace). In the D-Subspace the environment of the OA is presented by digital libraries (DiLibs [18]). The virtual machines are responsible for directly supporting the educational processes via implementing different specifications and concepts - SCORM engine (SEng, SCORM 2004 [19] implementation), Test Engine (TEng, QTI 2.1 standard [20] implementation) and an Events Engine (EEng, implements a special events model [21, 22] based on the Event Calculus formalism [23]). The A-Subspace provides all functionalities related to educational process organization, management and documentation in a secure manner - planning, logging and documentation of the educational process such as educational plans, programs and agendas, exam protocols, assessment results. The A-Subspace OAs support the execution and behavior of the two main active VES components - the student's Grade book (GB, developed in compliance with the Common Cartridge standard [15]) and the Teacher's notebook (TNB, enhancing the teaching process via analyzing the efficiency and progress level of all students in a given course). The contextual-awareness and intelligent behavior in the space must be supported by a structured in an intelligent manner data [24]. Thus, different educational ontologies are engineered to semantically enrich the agents' environment. The guards are a special kind of assistants that are responsible for the secure and efficient execution of the educational processes in the space. A distinctive characteristic of these assistants is that they are capable of operating in each and every part of the space, thus, the guards could be divided in two types - logical and virtual. The logical guards play a key role in the communication with the physical world by gathering the raw data from a single or a group of physical sensors further processed and transformed in a suitable format and model and shared with all other components in VES. In this aspect the logical guards could be defines as an interface between the physical and the virtual world in VES. The virtual guards operate entirely in the virtual space and they are capable of communicating with all other VES components seamlessly.

The educational portal DeLC is a special entry point of VES. Currently, there are two types of electronic education that are integrated in it - blended learning and lifelong learning. The portal provides different courses and testing functionalities [25] and is designed as a dynamic web application. The architecture ensures the ease of pluggability and integration of each of the VES's components in the portal - the three engines, GB and TNB. The portal is also integrated with the JADE platform [26] and the Jadex [27] container used to create agents that operate in the portal itself, thus, ensuring the seamless integration with the VES OAs.

$\begin{array}{lll}\text { (c) Инженерни науки, год. LV, 2018, № } 1 & 9 & \text { (c) Engineering Sciences, LV, 2018, No. } 1\end{array}$ 


\section{CONCEPTUAL MODELLING OF VES IN IoT}

To be able to put education in the terms of IoT a suitable virtualization of each and every aspect of the educational process as well as of the concept of knowledge must be defined. The models presented in [17, 28, 29] outline the key abstraction aspects that must be covered by an educational conceptualization and aim a more adaptive and agile learning process [30] as well as sharing and reusing of the educational content $[31,32]$. To be able to represent education via a formal model on a meta level, its base aspects (knowledge, processes and participants) must be modelled and formalized in a way that ensures the definition, finding and usage of relations between them, that provides their identification and definition of level of applicability into a specific educational context that is generated based on analyzing of all educational aspects, and all this must be defined and integrated within the frame of the target formal model.

\subsection{Conceptual model of VES}

Since VES is defined as an abstraction of the whole educational process that differentiates the various educational aspects but without breaking their interconnectivity [25], the formal model of VES must define a common abstraction of all educational aspects (knowledge, processes and participants). It must define the key behavioral, mental and properties characteristics of a VES component that are further specified in detail by the context of the concrete aspect of the whole educational process. Thus, VES modelling is based on polymorphic models over a common abstraction of an entity in VES (Fig. 2).

An entity in VES is a concept that is characterized with:

- Context-awareness of its environment;

- Capabilities for sensing and actuating its environment as well as its internal state based on shared contextual knowledge;

- Participation or initiation of actions or cooperation for achieving a certain goal;

- Interconnectivity and interactivity with all other entities in the space;

- Intelligence.

A significant concept in VES is the term environment. In VES definition the three aspects in which the concept environment can be defined are outlined - virtualization [33], education, space. The environment in VES is a virtualization of the real physical world and is a multidimensional space where

(c) Инженерни науки, год. LV, 2018, № $1 \quad 10$ (c) Engineering Sciences, LV, 2018, No. 1 


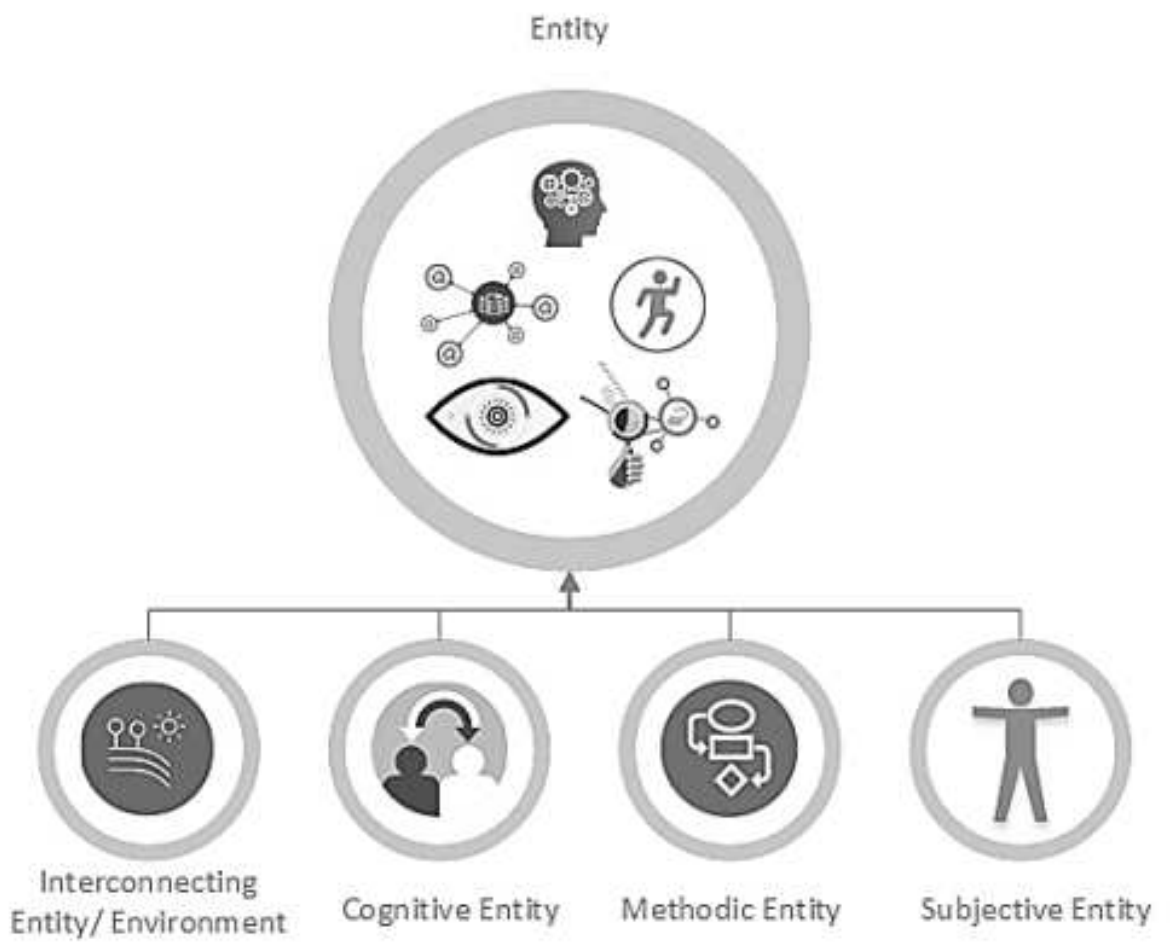

Fig. 2. VES entity model

Фиг. 2. Същностен модел на ВОП

the context is a function of the value sets of its dimensions (personal characteristics of a learner or a teacher, temporal situation, educational process stage, educational goals reached, etc.). Thus, the environment in VES is an intelligent and personalized information source with monitoring and reporting capabilities that is constantly interconnected with all other entities in the space. It is visible that the concept of environment extends the base entity conceptualization with context generation capabilities, inter-entities communication provisioning capabilities, dynamic internal structure, events generation, transfer and adaptability, responsibility to synchronize the real world with the virtual inner space. Thus, the concept of environment in VES's conceptual model can be defined as an interconnecting entity which makes it equal to all other entities in the space abstraction-wise. Knowledge in VES is the base informational mechanism that ensures the adaptability, proactivity, intelligence and context-awareness of the space. The information becomes knowledge when it can be meaningfully structured and put in the terms of a

(c) Инженерни науки, год. LV, 2018, № 1 
commonly adopted and comprehended dictionary (ontology). In the VES conceptualization terms, knowledge is a cognitive entity. The cognitive entities are the conceptual model of knowledge in VES and extend the concept of the abstract VES entity with the capabilities of acquiring and producing cognitive value. VES is an educational space which means that it has to implement real educational processes - methodic approaches for acquiring new knowledge by each of the participants being involved. The methodic entities extend the base abstract VES entity definition with a scenario-based and goal-oriented behavior internally implemented based on a certain adopted internal methodology. The participants in the educational space are conceptually modelled as subjective entities. These entities are the connection between the real physical world and the virtual space and are constantly interconnected which enhances their context-awareness of the real and the virtual environment. The subjective entity in VES extends the base abstraction VES entity definition with the concept of personal characteristics.

\subsection{The VES conceptual model in the terms of IoT}

To achieve a full conceptual compliance a bijection must be possible and made between the two sets of concepts - VES conceptual model and the Internet of Things paradigm. Moreover, VES must fully implement the IoT stack so that it integrates each and every aspect of the IoT paradigm.

The things are the base units in an IoT ecosystem. They implement the connection between the real physical world of objects and the digital world of Internet and all their specific characteristics are defined and classified by the IoT stack (Fig. 3). The VES's definition of the concept entity is fully compliant with the IoT thing definition. The VES entity concept is integrated in every component of the space since each one is a part of VES's conceptual entity hierarchy. Thus, the internal structure of VES is compliant with the IoT stack (Fig. 3) since it is implemented by IoT-compliant entities. Seamless connectivity and communication between the entities is another major aspect of the IoT paradigm. The things in IoT are expected to be constantly interconnected via the Internet network, thus, share information, produce and gain knowledge as a result of their seamless communication within the environment. The definition of the knowledge concept in both contexts - IoT ecosystem and VES - is equal. The stress is put on the social aspect of communication based on an appropriate infrastructure that enhances it. VES environment is designed to operate in a unified and abstract manner so that it enhances the communication between the VES entities in an intelligent and proactive way being a VES entity itself. The web-based communication is in the core of

(c) Инженерни науки, год. LV, 2018, № 1 


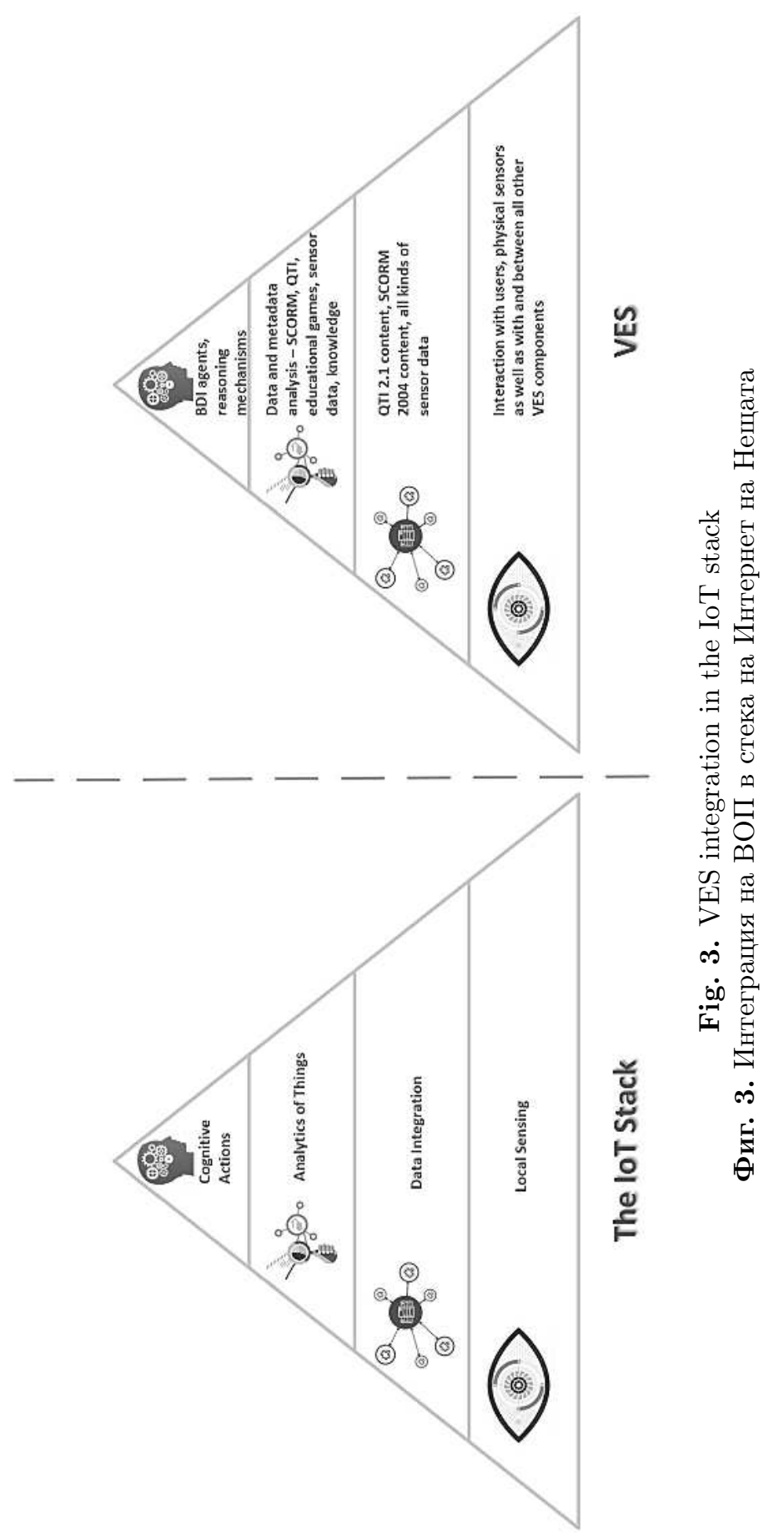

(c) Инженерни науки, год. LV, 2018, № 1

(c) Engineering Sciences, LV, 2018, No. 1 
the VES realization platform in IoT, thus, compliant with the paradigm. The concept of network connectivity, i.e. interconnectivity between all components in a space is adopted and implemented by the VES environment. VES and IoT could be defined as conceptually equal which provides great opportunities and brings out new horizons for evolving the education as an integrated part of the global IoT ecosystem.

\section{VES INTEGRATION PLATFORM}

Providing an integration platform for the realization of VES is the way for implementing it as an open ecosystem in the IoT world where people and things can cooperate as equal and intelligent entities in the educational context without being geographically, technologically, socially or conceptually limited.

\subsection{VIIP}

Figure 4 represents the generalized model of the VES IoT integration platform (VIIP) that aims realization of the space as an IoT ecosystem and addresses the dynamic and heterogeneous environment of connected devices, services and applications. The integration server can be logically separated into two main components - microservices and electronic content repositories.

The decomposition of VES functionalities via being provided as microservices aims achieving of scalability, security and efficiency of the management of the technologies and resources the space is built of. There are three main groups of microservices - system, educational and Content Access (CA). The system microservices (Things Integration, Rule Engine, Complex Events Processing) manage the common abstraction and behavior of the things in the VIIP. The educational microservices (Cognitive, Learning, Testing, Analytics) provide the educational processes implementation as well as proactive guidance for each participant. The CA microservices provide content management capabilities for each specific repository (Content storage) shared within and out of the platform. In the center of the platform is the BDI Rational Agents microservice that is accessible by all other platform components as they are all internally agent-based. Each platform component is accessible via a REST interface, thus, making it possible to integrate external applications, cloud services, IP and non-IP enabled (via an OSGi gateway) devices over a public API and via providing the suitable tools (SDK for mobile applications, Integration OSGi Framework for gateway-based solutions for non-IP enabled devices).

(c) Инженерни науки, год. LV, 2018, № 1 


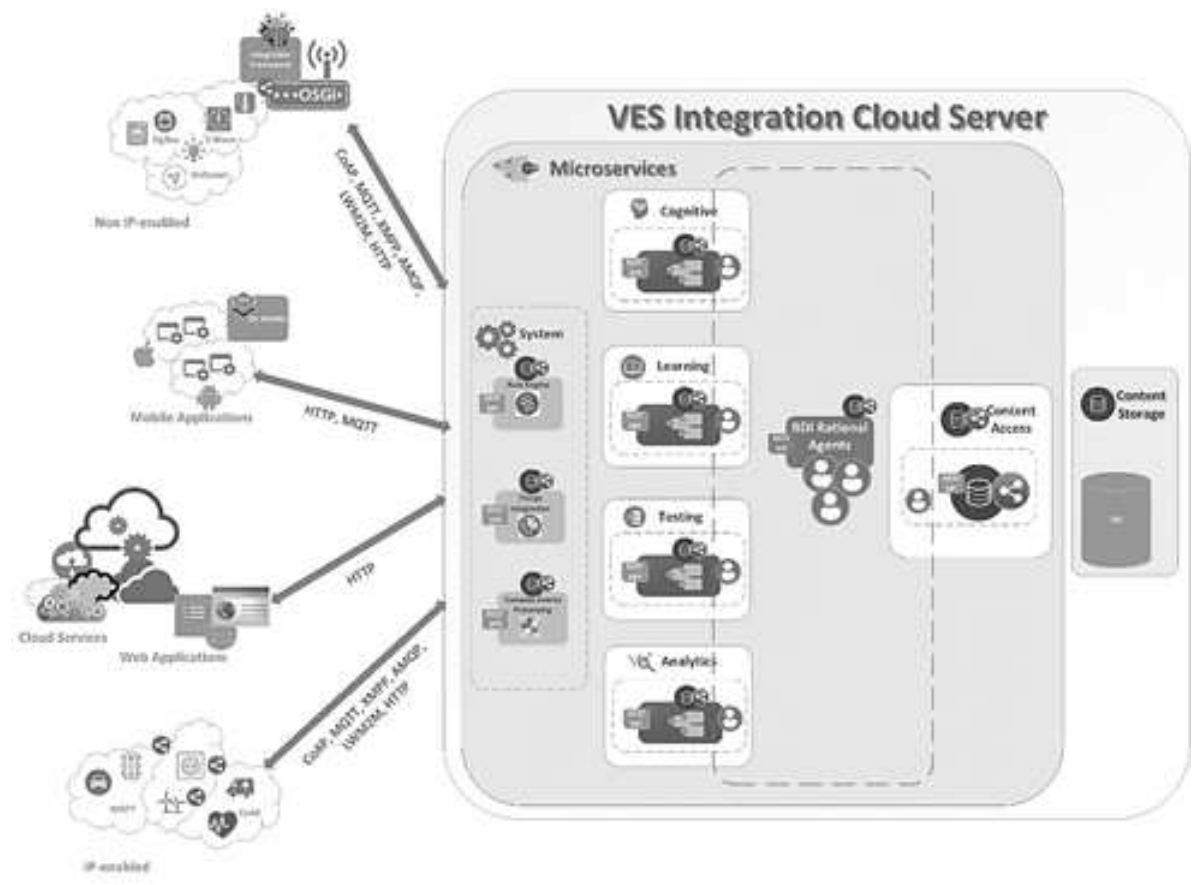

Fig. 4. VES IoT integration platform

Фиг. 4. ВОП Интернет на Нещата интеграционна платформа

\subsection{VIIP validation - integration of eTesting}

The initial work on the eTesting integration in VES [34, 35] are guided by several leading factors - DeLC educational portal, multi-agent platform and the QTI 2.1 standard for electronic testing content. These three preconditions are founder for the development and realization of eTesting in VES and determine the technologies and architectural approaches chosen so far.

Integrating eTesting in the VIIP overcomes all currently spotted technological and conceptual problems and follows a main methodology for integration of new components in the platform. All testing functionalities are provided as microservices in the platform using the core BDI Rational Agents microservice via its REST API for agents provisioning ensuring the intelligent and proactive behavior of the testing functionalities. A special QTI database is designed and implemented enhanced with a dedicated QTI Content Access microservice available in and out of the platform to manage the QTI standardized content. This way eTesting becomes an integrated part of VES being seamlessly interconnected with all its components transparently. All eTesting data and

(C) Инженерни науки, год. LV, 2018, № 1 
functionality is available in and out of the platform which ensures its seamless integration with all internal and external services and data in interest. Following the methodology for integration in VIIP, eTesting becomes an integrated part of the educational IoT ecosystem.

\section{CONCLUSION}

The world is on the edge of a new technological and software revolution that will inevitably influence each and every aspect of our lives. At the point where technologies have reached their optimum in the area they are intended for, a new horizons emerge when the goal becomes combining these technologies to implement a higher scope and functionalities based on them working in synergy and on a higher abstraction level. This is the driving force of the IoT paradigm adaptation that aims a full physical world virtualization that can bring out new and never seen before tendencies and phenomenons based on analytics and data integration provided by all things in the global IoT ecosystem. The education is an inseparable part of the human lives and mental evolution, thus, it has to make the technological and conceptual leap towards becoming an integrated part of the IoT ecosystem. Realizing it via a platform that provides transparent interconnection and integration within the global IoT ecosystem ensures its full and adaptable virtualization as well as clears the way for making even greater evolutionary steps towards the new humancentric paradigm expanding IoT - Internet of Everything.

\section{ACKNOWLEDGMENTS}

The research is partly supported by the NPD - Plovdiv University under Grant No. MU17-FMI-001 "EXPERT (Experimental Personal Robot That Learn)".

\section{REFERENCES}

[1] S. Stoyanov and I. Popchev, Evolutionary development of an infrastructure supporting the transition from CBT to e-Learning, Cybernetics and Information Technologies (2006) 6 (2) 101-114.

[2] S. Stoyanov et al., DeLC educational portal, Cybernetics and Information Technologies (2010) 10 (3) 49-69.

(c) Инженерни науки, год. LV, 2018, № 1 
[3] V. Valkanov, S. Stoyanov and V. Valkanova, Building a Virtual Education Space, The $19^{\text {th }}$ World Multi-Conference on Systematics, Cybernetics and Informatics, Orlando, Florida, USA, July 12-15, 2015, 322-326.

[4] N. Chilamkurti, S. Zeadally and H. Chaouchi, Next-generation wireless technologies: $4 G$ and beyond, Springer, London (2013) 190-192.

[5] S. Stoyanov et al., Service-oriented and agent based architecture supporting adaptable, scenario-based and context-aware provision of mobile e-learning services, International Journal of Computer Information Systems and Industrial Management Applications (2011) 3 771-779, ISSN 2150-7988.

[6] B. LiUET et al., Intelligent spaces: an overview, IEEE International Conference on Vehicular Electronics and Safety, 13-15 December 2007, Beijing, 978-1-42441266-2.

[7] F. W. WANG, Driving into the future with ITS, IEEE Intelligent System (2006) 21 (3) 94-95.

[8] A. K. DeY, Understanding and using context, Personal and Ubiquitous Computing Journal (2001) 5 (1) 4-7.

[9] A. K. Dey And G. D. Abowd. Towards a better understanding of context and context-awareness, in: Proceedings of the Workshop on the What, Who, Where, When and How of Context-Awareness, New York, ACM Press, 2000.

[10] M. H. Al-Sammarraie, Ph. D. Thesis: Policy-based approach for context-aware systems, Leicester, UK, STRL, De Montfort University (2011).

[11] F. Siewe, H. Zedan And A. CAU, The calculus of context-aware ambients, Journal of Computer and System Sciences (2010).

[12] V. VAlKAnov et al., AjTempura - first software prototype of C3A Model, IEEE International Conference Intelligent Systems'2014, at Warsaw, Poland, Volume: I, 2014, I, 427-435, DOI: 10.1007/978-3-319-11313-5_38.

[13] S. Stoyanov et al., A model of context-aware agent architecture, Comptes rendus de l'Academie bulgare des sciences: sciences mathematiques et naturelles (January 2014) 67 (4) 487-496.

[14] M. Wooldridge, An introduction to multiagent systems, Wiley (2009).

[15] IMS Common Cartridge Specification, https://www.imsglobal.org/cc/index.html, 18.02 .2018

[16] M. Wooldridge, Reasoning about rational agents, The MIT Press (2000).

[17] J. Todorov et al., Learning Intelligent System for Student Assistance - LISSA, IEEE $8^{\text {th }}$ International Conference on Intelligent Systems, 4-6 September, Sofia, 2016, 748-753.

(c) Инженерни науки, год. LV, 2018, № 1 
[18] A. Stoyanova-Doycheva et al., DiLibS platform for a Virtual Education Space, in: Proceedings of the 2015 Balkan Conference on Informatics, Advances in ICT, September 2015.

[19] SCORM 2004 Specification, http://adlnet.gov/adl-research/scorm/scorm-20044th-edition/, 18.02.2018

[20] IMS Question \& Test Interoperability Specification, https://www.imsglobal.org/question/index.html, 18.02.2018

[21] U. Westermann and R. Jain, Toward a common event model formula timed applications, IEEE Multi Media (2007) 14 19-29.

[22] S. Rafatirad, A. Gupta And R. Jain, Event composition operators, in: EiMM 2009, Proc. $1^{\text {st }}$ ACM Int. Presented at the Workshop on Events in Multimedia, New York, ACM, 2009.

[23] E. T. Mueller. Commonsense reasoning, An event calculus based approach, Elsevier (2015).

[24] D. Allemang And J. Hendler, Semantic web for the working ontologist (2011) Elsevier, ISBN: 978-0-12-385965-5.

[25] K. Gramatova et al., Integration of eTesting in an IoT eLearning ecosystem - Virtual eLearning Space, BCI'15, September 02-04, 2015, Craiova, Romania, 2015 ACM, ISBN 978-1-4503-3335-1/15/09, DOI: http://dx.doi.org/10.1145/2801081.2801086, Art. 14.

[26] F. Bellifemine, G. Caire and D. Greenwood, Developing multi-agent systems with JADE, Wiley (2007).

[27] Jadex Active Components, https://www.activecomponents.org/bin/view/About/New+Home, 18.02.2018

[28] D. HaY AND I. M. Kinchin, Using concept mapping to measure learning quality, Education \& Training (2000) 167-182, ISSN: 0040-0912.

[29] T. Kristensen et al., Towards a dynamic, content based e-learning platform (Ed. V. Uskov), Computers and Advanced Technology in Education, ACTA Press (2007) 107-114.

[30] T. Kristensen et al., Different E-learning paradigms - a Survey in Proceeding of MIT-LINC (Massachusets Institute of Technology Learning International Network Consortium, $4^{\text {th }}$ International Conference Technology-Enabled Education: a Catalyst for positive Change, Amman, Jordan, October 2007.

[31] J. G. Greeno, A. Collins and L. B. Resnick, Cognition and learning in D.C. Berliner (Eds Calfee R. C. Robert), Handbook of Educational Psychology, New York, Macmillan Library Reference, USA (1996).

[32] S. Eide, T. Kristensen and Y. Lamo, A model for dynamic content based e-learning system, in: ACM Proceedings EATIS, Aracaju, Brazil, 2008.

(c) Инженерни науки, год. LV, 2018, № 1

18

(C) Engineering Sciences, LV, 2018, No. 1 
[33] M. N. RAO, Cloud computing, PHI Learning Pvt. Ltd. (2015) 123-132.

[34] E. Doychev, K. Gramatova And N. Dimitrov, eTesting in Virtual eLearning Space, in: Proceedings of the International Conference "From DeLC to VelSpace", Plovdiv, 26-28 March 2014, Third Millennium Media Publications, ISBN: 0-9545660-2-5.

[35] S. Stoyanov et al., Virtual Education Space, The Journal of Applied Science, Applied Science University, Kingdom of Bahrain (2016) 1 (1) 24-40, ISSN 1764 2210 .

\title{
ИЗГРАЖДАНЕ НА ВИРТУАЛНО ОБРАЗОВАТЕЛНО ПРОСТРАНСТВО КАТО ИНТЕРНЕТ НА НЕЩАТА ЕКОСИСТЕМА
}

\author{
КонСТАНтина ГраматовА $^{1}$, СТАНИмиР Стоянов $^{1 *}$ и Иван ПоПЧев ${ }^{2}$ \\ ${ }^{1}$ Факултет по Математика и информатика, \\ Пловдивски университет „Паисий Хилендарски“, \\ бул. Бблгария № 236, 4027 Пловдив, Бблгария, \\ e-mails: konstantina.gramatova@gmail.com; stani@uni-plovdiv.net \\ ${ }^{2}$ Факултет по Икономика и сочиални науки, \\ Пловдивски университет „Паисий Хилендарски“, \\ ул. Цар Асен № 24, 4000 Пловдив, Бглгария, \\ e-mail: ipopchev@iit.bas.bg
}

Резюме. В статията са представени концептуалната и технологична дефиниция и инреграция на Виртуално Образователно Пространство (ВОП) в парадигмата Интернет на Нещата $($ ИнН), като ИнН екосистема посредством софтуерна интеграционна платформа (ВОП интеграционна платформа, ВОПИП). Описани са вътрешната структура, архитектура и характеристики на ВОП. Представен е йерархичният същностен модел на ВОП, както и е анализирана неговата концептуална съвместимост с парадигмата Интерет на Нещата. Направена е концептуална интеграция на ВОП в стека на Интернет на Нещата на база представения ВОП същностен модел, която да установи пълна съвместимост на дефинираната образователна екосистема с парадигмата Интернет на Нещата. ВОП интеграционната платформа е представена и валидирана чрез анализ на интеграция на електронно тестване в нея посредством следване и прилагане на общата, дефинирана за платформата, интеграционна методология.

Ключови думи: Интернет на Нещата, екосистема, образование, ВОП концептуален модел, ИнН интеграционна платформа.

Received February 19, 2018

(C) Инженерни науки, год. LV, 2018, № 1

19

(c) Engineering Sciences, LV, 2018, No. 1 